\title{
INVESTIGATING STEREOTYPES ABOUT THE TARGET LANGUAGE COUNTRY: A CASE OF GERMAN LANGUAGE LEARNERS *
}

\author{
INVESTIGANDO LOS ESTEREOTIPOS SOBRE EL PAÍS DE UNA \\ LENGUA OBJETIVO: UN CASO DE ESTUDIANTES DE LENGUA \\ ALEMANA
}

\author{
LARISA NIKITINA \\ University of Malaya. Kuala Lumpur, Malaysia \\ larisa@siswa.um.edu.my \\ ZURAIDAH BINTI MOHD DON \\ University of Malaya. Kuala Lumpur, Malaysia \\ zuraida@um.edu.my \\ LOH SAU CHEONG \\ University of Malaya. Kuala Lumpur, Malaysia \\ lohsch@um.edu.my
}

\begin{abstract}
Language learners bring into the classroom a multitude of stereotypes about the target language country, culture and native speakers. Recognizing an important role that these images play in the process of learning a foreign language, several research studies have explored stereotypes held by language learners. For the most part, these studies were qualitative in nature and they mainly focused on the stereotype content. There is also a lack of studies that examine frequency and salience of the stereotypical images about Germany held by the learners of German. The current mixed methods study addresses these gaps. It extends research on stereotypes in the field of applied linguistics by qualitatively exploring the content and quantitatively assessing favourability and salience of the language learners' stereotypical images. This study was conducted among beginner learners of German in a big public university in Malaysia. The findings revealed that the students' stereotypes about Germany included references to sport, science, technology, industry, culture, history,
\end{abstract}

*The article submitted to your esteemed journal is a part of my $\mathrm{PhD}$ thesis. The two co-authors of the article are the thesis supervisors. The topic of my $\mathrm{PhD}$ thesis has been presented at and approved by the Institute of Graduate Studies, University of Malaya. This study is the first of a kind research on language learners' stereotypes done in the Malaysian educational context. 
people, language, geography and food. The most salient stereotypes were "football", "cars", "technology", "engineering", "Volkswagen" and "big industries." For the most part, the stereotypes about Germany held by the students were positive.

Keywords: Country stereotypes, foreign language learners, stereotype favourability, stereotype salience, mixed methods.

\section{RESUMEN}

Los alumnos traen a la clase una multitud de estereotipos sobre la lengua a estudiar, la cultura y también sobre los hablantes nativos. Reconociendo el importante papel que éstos juegan en el proceso de aprendizaje de una lengua extranjera, se han llevado a cabo varias investigaciones que han explorado los estereotipos que los estudiantes de idiomas poseen. En su mayor parte, estos estudios fueron de carácter cualitativo y se centraron principalmente en el contenido de los estereotipos. No existen suficientes estudios que examinen la frecuencia y la relevancia de los estereotipos que se han divulgado entre los estudiantes de alemán. Los actuales métodos-mixtos se encargan de estudiar estos vacíos. Se ha extendido la investigación sobre los estereotipos en el campo de la lingüística aplicada para explorar cualitativamente el contenido y evaluar cuantitativamente la relevancia de las imágenes estereotipadas en los alumnos de idiomas. Este estudio se realizó con alumnos principiantes de la lengua alemana en una gran universidad en Malasia. Los resultados revelaron que los estereotipos de los estudiantes sobre Alemania incluían referencias deportivas, científicas, tecnológicas, industriales, culturales, históricas, sobre su gente, su lenguaje, su geografía y la riqueza culinaria. El estereotipo más representativo fue el fútbol, los automóviles, la tecnología, la ingeniería, Volkswagen y las grandes industrias. La mayoría de los estudiantes tenían estereotipos muy positivos con respecto a Alemania.

Palabras clave: Estereotipos de un país, estudiantes de lengua extranjera, aspectos positivos de un estereotipo, relevancia de un estereotipo, métodos mixtos.

Recibido: 14.01.2014. Aceptado: 04.07.2014.

\section{INTRODUCTION}

Country and national stereotypes are tenacious social and psychological constructs. Language learners bring into the classroom an array of images about the target language (TL) country and culture and these images are often stereotypical in nature. As Dlaska (2000: 260) noted, even in the beginner language classroom "stereotypes are always already there". Lippmann (1965 [1922]) who introduced the concept of stereotypes into the Social Sciences and Humanities 
recognized that stereotypes embed and reflect people's attitudes toward the surrounding world. As he wrote, "The stereotypes are ... highly charged with the feelings that are attached to them" (Lippmann, 1965 [1922]: 64). The close links between stereotypes and attitudes have been recognized and widely researched by psychologists (Forest \& Silvert, 1951).

In the field of applied linguistics language learners' attitudes toward the TL country, culture and speakers have been recognized as an important factor in the students' motivation to learn a foreign language. This view has been prominent since Gardner and Lambert (1972) introduced a notion of integrative orientation or integrativeness, which incorporates the language learners' positive attitudes toward and a genuine interest in the culture and speakers of the target language. Since Gardner and Lambert's pioneering research assessments of language learners' attitudes toward the target culture and speakers have been done by employing instruments containing sets of close-ended questionnaire statements, such as the Attitude Motivation Test Battery (AMTB) (Gardner \& Smythe, 1981). While this approach allows measuring language learners' attitudes toward the TL country and culture it does not permit the respondents to express their own perceptions and beliefs about the research object. This could impose some limitations to a scholarly enquiry because language learners often lack direct contacts with the target culture and due to this fact their knowledge about it can be very limited (Kormos \& Csizér, 2007). Therefore, hinging the assessment of the language learners' attitudes on a set of pre-determined by the researcher questions could preclude a fuller exploration and a more precise measurement of the students' cultural knowledge and attitudes.

The present study employs a free-response approach to soliciting language learners' stereotypes and attitudes toward the target language country, Germany. The term "stereotype" is used here in the broadest sense to include any image about the TL country, culture and native speakers. Of particular interest for the present inquiry are cultural stereotypes about Germany. In social psychology, an image mentioned by "a substantial percentage" of the participants is recognized as a cultural (or consensual) stereotype about the study object (Spencer-Rodgers, 2001: 643). An important implication is that a cultural stereotype needs to be shared by a group of people rather than expressed in various ways by the same individual (cf. Spencer-Rodgers, 2001). There is no universally accepted benchmark for distinguishing cultural stereotypes and this "substantial percentage" has varied in the previous studies between 6\% (Marín, 1984) and 20\% Niemann, Jennings, Rozelle, Baxter \& Sullivan (1994). The current inquiry adopts a 10\% benchmark, as it was done by Spencer-Rodgers (2001). The term "cultural stereotypes" in this study refers to the mental images about Germany, its culture and people provided by ten percent and above of the language learners.

The aims of this study are two-pronged. Firstly, it seeks to investigate the 
students' stereotypes about and attitudes toward the TL country, culture and native speakers. Secondly, it endeavours to demonstrate how approaches and techniques adapted from various academic disciplines, such as social psychology (Spencer-Rodgers, 2001) and anthropological linguistics (Sutrop, 2001) can be used for a more rigorous and systematic exploration and measurement of language learners' stereotypes and attitudes toward the TL country. This approach aligns with a view that Applied Linguistics is an "interdisciplinary field" that speaks with multiple voices (Kramsch, 2000: 316-317).

The present study raises the following questions:

(1) what cultural stereotypes about Germany do beginner learners of German have?

(2) are these stereotypes positive or negative?

(3) what are the students' most salient cultural stereotypes about Germany?

\section{LITERATURE REVIEW}

\subsection{The origins of the construct}

American journalist Walter Lippmann (1889-1974) is credited to be the person who brought the concept of stereotypes into the Social Sciences and Humanities. In his widely acclaimed book "Public Opinion" written in 1922, Lippmann devoted a whole chapter to stereotypes and described them as "pictures in our heads" (Lippmann, 1965 [1922]: 3). Concerning the origin of stereotypes Lippmann argued that they germinate within a culture. In his own words, "In the great blooming, buzzing confusion of the outer world we pick out what our culture has already defined for us, and we tend to perceive that which we have picked out in the form stereotyped for us by our culture" (5). Being culturally-bound, stereotypes are perpetuated within a culture through various types of discourses so that individuals acquire them since childhood from "parents, teachers, priests, and uncles" (Lippmann, 1965 [1922]: 61). The inseparability of stereotypes from culture and their central function in human cognitive processes helps to elucidate the tenacious and pervading nature of stereotypes.

Despite a tendency to assign negative connotations to the word "stereotype", which can be due to the links between stereotypes and prejudice highlighted by Allport (1954), stereotypes are not necessarily negative. Furthermore, they play an important function as an energy-saving psychological device that helps people to deal with a barrage of new information. Noting people's tendency toward stereotyping, Lippmann (1965 [1922]) observed that "there is economy in this. For the attempt to see all things freshly and in detail, rather than as 
types and generalities, is exhausting, and among busy affairs practically out of the question" (59).

Lippmann's treatise on stereotypes has presaged much of the ensuing empirical research on this psychological construct. Many of the themes raised by Lippmann remain important research topics until the present time. Among them are the origin and functions of stereotypes, their accuracy, favourability and the ability to influence people's behaviour or behavioural intentions. Exploring language learners' stereotypes can help language educators to evaluate the students' beliefs and knowledge about the TL country, to measure their attitudes toward it and to make empirically-driven pedagogical decisions.

\subsection{Stereotype measurement techniques: Check-list vs. free-response}

There are two major approaches in psychology to investigating stereotypes, namely, check-list and free-response (Stangor \& Lange, 1994). The check-list technique was introduced by Katz and Braly (1933) who prepared a research instrument containing the names of several ethnic and national groups and an inventory of 84 trait adjectives. The researchers then asked their respondents to mark the traits that they considered as the most typical of each particular ethnic or national group in the list. An alternative to this approach is the free-response technique in which the respondents are asked to indicate the thoughts that come to their minds when they think of the study object. In other words, the participants are free to provide their own images or descriptions of the objects, people, events or phenomena under study.

Both procedures have their own merits and disadvantages. For example, on the positive side, the use of the preselected lists of items allows the researchers to replicate a study and make comparisons between stereotypes in various social and cultural contexts or at different points of time. This explains the lasting appeal of Katz and Braly's (1933) study. The drawback of this technique is that the data collected or stereotypes reported in the findings could be "an artefact of research methodology" (Spencer-Rodgers, 2001: 642) whereby participants simply endorse the traits on the list including those which they would not have mentioned themselves. Moreover, as Ehrlich and Rinehart (1965) demonstrated, some of the respondents had assigned to the social groups under study various characteristics from the check-list even if they had never encountered -and had no prior knowledge of- this particular ethnic group.

Regarding the free-response technique, the main advantage is that it allows the respondents to list their own images about the study object. The data thus obtained allow the researcher to detect stereotypes that are most strongly associated withand that are the most salient about-the objects under study (Ehrlich \& Rinehart, 
1965; Niemann et al., 1994; Spencer-Rodgers, 2001). Free-response technique has several shortcomings as well. Among them is a possibility that the respondents may omit some important traits that do not come readily to their mind and a tendency to give socially desirable answers. Besides, there are difficulties associated with the analysis of the data obtained by the means of open-ended questions, such as data organization and coding, data synthesis and interpretation of the results (Spencer-Rodgers, 2001).

\subsection{Stereotypes about Germany and the Germans}

The first empirical study on stereotypes about the German people was done by Katz and Braly (1933). The researchers asked 100 Princeton university students to select among the list of 84 adjectives the traits they considered characteristic of various national groups, including the Germans. The students were also instructed to add their own descriptors should the list omit some features they considered important. As the findings of the study revealed, "scientificallyminded", "industrious", "stolid", "intelligent", and "methodical" were the top five characteristics of the German people. The researchers concluded that the traits assigned by the students to the German people were "consistent with the popular stereotype to be found in newspapers and magazines. Their science, industry, ponderous and methodical manner, and intelligence were pointed out by over one-fourth of the students" (Katz \& Braly, 1933: 285).

In research literature on language learners' stereotypes about the TL country, culture and native speakers, studies done among the learners of German are well represented. However, the scholarly literature written in English is limited to the US educational contexts. One of the earliest studies on cultural clichés about Germany was done by Taylor (1977) who had asked 44 beginner learners of German in an American college to answer three questions, namely, "1. What geographical places come to your mind when you think of Germany? 2. What other associations do you have with Germany, past and present? 3. Which are German-speaking countries?”. In their answers to the first question the students repeatedly mentioned "Munich, Berlin, Rhine, Hamburg, Black Forest, Berlin Wall, Frankfurt, Cologne, Heidelberg, Alps, Bonn, Bavaria” (Taylor, 1977: 112). Among the frequent answers to the second question were "folklore, wars, Hitler, beer, ties through family and/or friends, Olympics, classical music, food, Nazism"; also, the students provided several "stereotyped national traits" unspecified by the author. The students' responses to the third question included such countries as "Germany, Austria, Switzerland, Luxembourg, Belgium" as well as several other unspecified countries in Europe and other parts of the world. Analyzing these findings, Taylor (1977) concluded that the students' images about the TL country 
were highly stereotypical.

A study by Schulz and Haerle (1995) elicited stereotypes about the German people held by 340 learners of German in an American college. The researchers asked the participants in their study to complete the phrase "Die Deutschen ...". Analysis of the data yielded eight main categories of stereotypical images held by the students, namely: (1) personal characteristics of the German people (e.g., "friendly", "intelligent", "hardworking", "reserved"), (2) the Germans' love of beer, (3) cars (e.g., "they make excellent cars", "have many cars"), (4) the country or language (e.g., "beautiful country", "difficult language"), (5) schooling or culture (e.g., "(they) have interesting /rich culture", "(they are) well-educated"), (6) physical attributes (e.g., "good looking", "tall”), (7) history or historical events (e.g., "interesting history", "(Germany is) now reunited"), and (8) food and eating ("they eat sauerkraut", "they have many cakes"). Schulz and Haerle (1995) observed that there was a lack of references to important political and historical events in Germany; also absent were the images related to cultural phenomena and great scientific achievements. It should be noted that the research instrument may be accountable for the images produced by the students because the phrase "Die Deutschen ..." might have prompted the respondents to focus on national character and physical attributes of the German people rather than on the cultural, political, historical or scientific events in Germany.

Abrams (2002) posed a more encompassing question to her respondents who were 68 intermediate level students of German in a large American university. She asked them to provide as many answers as they can to the question "What do you know about Germans/Germany, Austrians/Austria, the Swiss/Switzerland or any of the other German-speaking countries?". The findings revealed that the references to beer, foods (e.g., "bratwurst") and Germany's rich history dominated among the students' answers. On the other hand, there were only a few descriptions of the German people character (e.g., "friendly", "punctual", "eat a lot") and a small number of images mentioning "soccer", a "different school system" and "the German language”.

A more recent study by Chavez (2009) explored language learners' stereotypes about the German language. The researcher employed both closed-ended and open-ended questions. As Chavez (2009: 8) noted, stereotypical perceptions of German as "a harsh, throaty, or 'phlegmy' language" are abundant and these images are promoted in the mass media and through the TV programs and the movies. The problem with this stereotype is that the perceived harshness of the language is extrapolated to native speakers of German who are viewed as "aggressive" people (Chavez, 2009: 17). The findings of the study indicated that the beginner learners of German had less of the preconceived notions about the target language compared to the learners at more advanced levels. For example, the students in their second, third and fourth year of study tended to have negative perceptions about German 
pronunciation and they described it as "harsh" or "hacking". However, quite unexpectedly, the "harsh-sounding" characteristic had a positive connotation for some students who stated that they chose to study German because it sounded unique and different and because it was not "a sissy language" (Chavez, 2009: 6). Also, the respondents described German grammar as "strange", "difficult" and "backwards" in a sense that it had a "backwards syntax of English".

As the review of literature provided in this sub-section indicates, the wording of the research question determines the range and scope of the answers about the TL country. Also, some of the studies had reported frequencies or commented on the prominence of the stereotypical images about Germany. However, it is impossible to discern which of the images were the most salient and which were the least salient.

\subsection{Favourability of language learners' stereotypes about Germany}

In several studies on language learners' stereotypes about Germany, attempts were done to classify the images into positive, negative or neutral. For example, Schulz and Haerle (1995) concluded that their respondents had mostly positive images about the TL country and the German people. Taylor (1977) assumed that the learners' references to 'good old Germany' were clearly positive in nature. However, these conclusions relied on heuristics or common sense about the nature of positive and negative phenomena rather than on a quantitative assessment of the images generated by the respondents. Besides, the conclusions reached by the researchers may not reflect the respondents' own evaluation of their images. For example, Schulz and Haerle (1995) classified the descriptors "stolz" "proud") or "mit viel Gefühl" ("with much feelings", "emotional") as positive images while the respondents could have attached a positive, a neutral or even a negative meaning to them. On the other hand, the image "serious" which the authors considered neutral could be classified by the respondents as positive or negative.

A possibility of such misinterpretations has surfaced quite poignantly in Chavez' (2009) study which discovered that a seemingly negative descriptor "harsh-sounding language" could in fact have positive connotations for some of her respondents. She cited one student who had considered the "harsh" sound of German as dissimilar to some "sissy languages" and therefore attractive and "cool" (Chavez, 2009: 6). All of these considerations highlight the need for a different and more explicit approach to gauging favourability of the language learners' country images. Some steps in this direction have been taken by researchers. For example, Nikitina and Furuoka (2013) in their study on stereotypes about China

held by learners of Mandarin asked the respondents to assign a favourability rating 
to each image on a scale ranging from -3 (for the most negative images) to +3 (for the most positive images). The ensuing analysis and discussion in their study were based on the learners' own evaluations of the images about the target language country.

\section{BACKGROUND TO THE STUDY}

Malaysia is a Southeast Asian country with a population of 30 million people. There are several major ethnic groups in the country, such as Malays, Chinese, Indians and various indigenous people. Bahasa Malaysia (the Malaysian language) is the official language but English is widely spoken. A fact that English is taught as a second rather than a foreign language at primary and secondary schools in Malaysia testifies to the status of English in the country. On the other hand, foreign languages are not a part of the curriculum at primary and secondary levels of education. Some schools do offer foreign languages as elective subjects; however, the choice is often limited to either Arabic or Mandarin due to cultural significance of these languages in Malaysia.

At a tertiary level, all public universities in Malaysia offer various foreign language courses, including European and Asian languages. German is taught in several major public and private universities and colleges. In the University of Malaya, where this study was conducted, German as a generic course is offered at levels 1, 2 and 3. The students, however, are not required to complete all of the three levels of the language program. They can learn German for one semester and choose another language program in the following semester or just discontinue taking any language classes.

\section{METHOD}

\subsection{Participants}

Twenty-six beginner learners of German in the University of Malaya participated in this study. Among the participants, twenty-two (84.6\%) students were Malaysians of various ethnic backgrounds including the Chinese ( $\mathrm{n}=14$ or $53.8 \%$ ), the Malays $(\mathrm{n}=4$ or $15.4 \%)$ and the Indians $(\mathrm{n}=4$ or $15.4 \%)$. Four $(15.4 \%)$ respondents were international students. They hailed from Spain ( $\mathrm{n}=2$ or $7.75 \%)$, Uzbekistan $(\mathrm{n}=1$ or $3.8 \%)$ and Bangladesh ( $\mathrm{n}=1$ or $3.8 \%)$. There were slightly more male $(\mathrm{n}=15$, $57.7 \%)$ than female $(\mathrm{n}=11,42.3 \%)$ students among the respondents. The age of the participants ranged between 20 and 24 years old. 


\subsection{Data collection and instrument}

Data for this study were collected during German language classes in the academic year 2012/2013. Each student received a photocopied form with the question "What images or mental pictures come to your mind when you hear the words 'Germany' and 'German'?". The students were asked to write their answers in short phrases or words and they could supply as many images as they thought was necessary to convey their impressions about the TL country. After the students had finished writing their images they were instructed to assign a favourability rating to each image in their lists using a scale from -2 (for very negative images) to +2 (for very positive images). The respondents were also asked to provide some information about their background, such as age, gender and ethnicity/nationality.

\subsection{Data organization and analysis}

First of all, each questionnaire was given an identification number by the researcher. Then, the students' images about Germany were typed ad verbatim in the Microsoft Word format together with the questionnaire's identification number, the favourability rating given to each image by each respondent and the sequence number with which each image appeared on the individual list of images. Content analysis of the images was conducted after the data were organized.

The images provided by the students were analyzed using open-coding procedure where the emergent themes are established in the course of the analysis (Ryan \& Bernard, 2003). Data processing techniques employed for the analysis were word lists and frequency count. The word list technique is appropriate for analyzing verbatim data consisting of short words and phrases (Ryan \& Bernard, 2003). A $10 \%$ benchmark was adopted in this study to distinguish the cultural stereotypes about Germany, which means that an image was considered as a cultural stereotype only if $10 \%$ of the respondents (rounded to $n=3$ or three persons) or more had mentioned this particular image. In the cases when the same respondent had provided similar images (e.g., "cars", "Automobile", "das Auto") these images were not considered as forming a cultural stereotype.

Analysis of qualitative data by necessity involves personal judgments, "hunches and intuitions" on the part of the researcher (Ryan \& Bernard, 2003: 94). It is important, however, that the researcher establishes logic and develops a protocol to be followed during the analysis as this would promote coherence and consistency of the decision making process. The logic governing content analysis in the present study was as follows. In the initial stage, we grouped similar or semantically 
close images about Germany into separate categories. For example, the students' references to "cars", "Volkswagen", "BMW", "Mercedes Benz" and "Audi" were grouped under the category labelled "Cars". This label was chosen because the majority of the answers in this category were -literally- "cars". Because we aimed at a 'fine-grained' analysis and sought to identify as many cultural stereotypes about Germany as possible, we subtracted from the larger and more general categories those images that could form their own distinct groups.

To be more precise, if an image within a large initial category, such as "Cars", was mentioned by three or more different respondents (e.g., "Volkswagen") the image was recognized as a cultural stereotype and it was subtracted from the larger group to form its own category. An appropriate label was assigned to the new category (i.e., "Volkswagen"). Though this approach resulted in the presence of some overlapping categories it also helped to gain deeper insights into the nature and salience of the cultural stereotypes about Germany. At the same time, the images that had been mentioned only once or twice (e.g., "Audi" and "Porsche") were retained in the category "Cars" because they did not achieve the required frequency of $10 \%$ to become a cultural stereotype and to form a new category.

\subsection{Calculation of stereotypes' favourability}

Favourability ratings given by the respondents to each of the images in the categories that were formed during the first step of the analysis were used to calculate mean valence of each category of cultural stereotypes. The following formula was employed for this purpose:

$$
M V_{j}=\frac{\sum_{j=1}^{F_{j}} V_{j i}}{F_{j}}
$$

where $M V_{j}$ is mean valence of the category $j ; V_{j i}$ is the valence rating given by a student $i$ to an image $j$ in this category of images; $F_{j}$ is the frequency with which the image $j$ was mentioned. For example, the frequency with which the image "Hamburg" was mentioned is $3\left(F_{j}=3\right)$. Each student had assigned his or her own favourability rating to this image on the scale ranging from -2 to +2 . Employing formula (1), the mean valence index for "Hamburg" was calculated at $1.3333(M V=1.3333)$. To ensure a high accuracy the calculations were done using Microsoft Excel software. 


\subsection{Calculation of stereotypes' salience}

Realizing that it is important to assess not only frequency with which the images about the TL country were provided by the language learners but also how salient these images were, this study calculated salience index of the cultural stereotypes about Germany. We used the following user-friendly formula proposed by Sutrop (2001):

$$
C S_{j}=\frac{F_{j}}{N\left(m P_{j}\right)}
$$

where $C S_{j}$ is the cognitive salience index of the category $j ; F_{j}$ is the frequency with which the image $j$ was mentioned; $m P_{j}$ is the mean position of the image $j$. The mean position can be calculated as:

$$
m P_{j}=\frac{\sum_{i=1}^{N} R_{j i}}{F_{j}}
$$

where $R_{j i}$ is the rank of the image $j$ assigned by the student $i$. The rank of the first image in the list of images is codified as 1 ; if the image occupies the second position in the list it is codified as 2 and so on. To give an example, employing formulas (2) and (3), the cognitive salience (CS) index of the "beautiful landscape" image was calculated as:

$$
F_{j} / N(m P)=2 / 3\left(\frac{1+4+0}{2}\right)=\frac{2}{7.5}=0.26
$$

\section{FINDINGS}

The students provided a total of 197 images about Germany. Of them, 182 images were grouped into 44 categories each containing between 2 and 12 images. The remaining 15 images were idiosyncratic which means that each of these images had been mentioned only once and none of them could be grouped into any of the categories that had emerged during the analysis. "Grey colour" is one example of the idiosyncratic images about Germany given by the respondents. 


\subsection{Research question 1: Cultural stereotypes about Germany}

Initially, 44 categories of images about Germany were identified in the course of the qualitative analysis of the data. Not all of these categories were cultural stereotypes because the number of images in some categories was $2(n=2)$, which was below the established benchmark of $10 \%(n=3)$ that was required to form a cultural stereotype.

Employing the minimum 10\% $(\mathrm{n}=3)$ benchmark and making sure that these representations were mentioned by three different persons, we identified 29 categories of cultural stereotypes about Germany. Table I shows these stereotypes in descending order of frequency $(F)$. Also reported in the table are: the frequency rank $(F r R)$, the mean valence $(M V)$, the favourability rank $(F a R)$, the cognitive salience $(C S)$ index and the salience rank $(S R)$ of each cultural stereotype.

As Table I shows, the images concerning cars, technology, industry, science and engineering were especially prominent among the cultural stereotypes about Germany. It also should be noted that besides a somewhat abstract image "cars" the cultural stereotypes about Germany included specific brands of cars, such as "Volkswagen" and "BMW". Also prominent among the cultural stereotypes were the images concerning modern German history as reflected in the presence of such categories as "Hitler", "Berlin Wall", "World War II", "Nazi" and "interesting history".

Four categories of images were related to geography; they contained the references to cities in Germany (i.e., "Berlin" and "Hamburg"), the descriptions of landscape (i.e., "beautiful landscape") or the mentions of "four seasons". German culture was represented by such categories as "Oktoberfest", "German culture" and "99 Luftballons" (a pop song). Three categories of the cultural stereotypes were food-related; among them were "sausages", "beer" and "foods". Furthermore, the respondents shared the images of the Germans as a "disciplined people"; of Germany as a "peaceful country" and of German as a "unique language".

Table I: Frequency, favourability and salience of cultural stereotypes about Germany ${ }^{1}$.

\begin{tabular}{|r|l|r|r|c|r|c|c|}
\hline No & Category & $\boldsymbol{F}$ & $\boldsymbol{F r} \boldsymbol{R}$ & $\boldsymbol{M V}$ & $\boldsymbol{F a R}$ & $\boldsymbol{C S}$ & $\boldsymbol{S R}$ \\
\hline 1 & Football & 12 & 1 & 1.3333 & 18 & 0.1153 & 1 \\
\hline 2 & Cars & 10 & 2 & 2 & 1 & 0.1068 & 2 \\
\hline 3 & Technology & 9 & 3 & 1.8888 & 5 & 0.0973 & 3 \\
\hline 4 & Developed country & 8 & 4 & 1.625 & 15 & 0.0397 & 12 \\
\hline
\end{tabular}

${ }^{1}$ Note: F means "frequency"; FrR is "frequency rank"; MV is "mean value"; FaR is "favourability rank"; SC stands for "cognitive salience" index; SR is "salience rank". 
RLA. Revista de Lingüística Teórica y Aplicada, 52 (2), II Sem. 2014

Continuation Table I.

\begin{tabular}{|r|l|r|r|l|r|r|r|}
\hline 5 & Big industries & 6 & 5 & 1.6666 & 11 & 0.0532 & 8 \\
\hline 6 & Volkswagen & 6 & 5 & 1.8333 & 6 & 0.0576 & 6 \\
\hline 7 & Science and scientists & 6 & 5 & 1.6666 & 11 & 0.0251 & 22 \\
\hline 8 & Engineering & 6 & 5 & 2 & 1 & 0.0629 & 5 \\
\hline 9 & Difficult language & 6 & 5 & -0.4 & 26 & 0.0152 & 27 \\
\hline 10 & BMW & 5 & 10 & 2 & 1 & 0.0801 & 4 \\
\hline 11 & Oktoberfest & 5 & 10 & 0.8 & 23 & 0.0274 & 18 \\
\hline 12 & Sausages & 5 & 10 & 1.6 & 16 & 0.0274 & 19 \\
\hline 13 & Hitler & 5 & 10 & -1 & 27 & 0.0400 & 11 \\
\hline 14 & Berlin Wall & 5 & 10 & 1 & 20 & 0.0369 & 14 \\
\hline 15 & Disciplined people & 5 & 10 & 0.8 & 23 & 0.0228 & 24 \\
\hline 16 & German culture & 4 & 16 & 1.5 & 17 & 0.0512 & 9 \\
\hline 17 & Beer & 4 & 16 & 1.75 & 7 & 0.0246 & 23 \\
\hline 18 & World War II & 4 & 16 & -2 & 29 & 0.0146 & 28 \\
\hline 19 & Song “99 Luftballons" & 4 & 16 & 1.75 & 7 & 0.0410 & 10 \\
\hline 20 & Berlin & 4 & 16 & 1.75 & 7 & 0.0559 & 7 \\
\hline 21 & Four seasons & 4 & 16 & 1 & 20 & 0.0323 & 15 \\
\hline 22 & Peaceful country & 4 & 16 & 1 & 20 & 0.0279 & 17 \\
\hline 23 & Unique language & 4 & 16 & 1.75 & 7 & 0.0267 & 20 \\
\hline 24 & Beautiful landscape & 3 & 24 & 2 & 1 & 0.0266 & 21 \\
\hline 25 & Bayern Munich team & 3 & 24 & 1.6666 & 11 & 0.0288 & 16 \\
\hline 26 & Nazi & 3 & 24 & -1.6666 & 28 & 0.0216 & 25 \\
\hline 27 & Hamburg & 3 & 24 & 1.3333 & 18 & 0.0384 & 13 \\
\hline 28 & Interesting history & 3 & 24 & 0.3333 & 25 & 0.0164 & 26 \\
\hline 29 & Foods & 3 & 24 & 1.6666 & 11 & 0.0119 & 29 \\
\hline
\end{tabular}

\subsection{Research question 2: Favourability of cultural stereotypes about Germany}

An overwhelming majority of the cultural stereotypes about Germany, or 25 out of 29 categories, were positive. The images "cars", "engineering", "BMW" and "beautiful landscape" had the highest possible mean valence $(M V=2)$. This means that all of the respondents who mentioned these images assigned them the highest favourability rating $(+2)$. As a result, these cultural stereotypes occupied the top position according to their favourability ranks $(F a R=1)$. The images "technology" $(M V=1.8888 ; F a R=5)$ and "Volkswagen" $(M V=1.8333 ; F a R=6)$ followed closely behind.

Only 4 out of 29 cultural stereotypes about Germany had negative mean valence values. Three of these stereotypes were related to the Second World War. These images were: "World War II" $(M V=-2 ; F a R=29)$, which was the most negative stereotypical image, "Nazi" $(M V=-1.6666$; FaR $=28)$ and "Hitler" $(M V=$ 
Investigating stereotypes about the target language country: A case of German language learners / L. Nikitina, Z. Binti, L. Sau

$-1 ; F a R=27)$. One of the four cultural stereotypes with negative mean valence values was "difficult language" ( $M V=-0.4 ; F a R=26)$; it could be considered as a mildly negative image.

\subsection{Research question 3: Salience of cultural stereotypes about Germany}

The findings show that the cultural stereotypes with frequency ranks from 1 to 5 were also among the most salient images about Germany. These stereotypes were "football" $(F r R=1 ; S R=1)$, "cars" $(F r R=2 ; S R=2)$, "technology" $(F r R=3 ; S R=3)$, "engineering" ( $F r R=5 ; S R=5)$, "Volkswagen" $(F r R=5 ; S R=6)$ and "big industries" $(F r R=5 ; S R=8)$. This means that, apart from the image "football", the images that came most readily to the respondents' minds related to German cars, industry and technology. To concur, the image "BMW", although less frequent, had a high salience rank $(F r R=10 ; S R=4)$. Among the top ten most salient images about Germany were included "Berlin" ( $F R=16 ; S R=7)$, "German culture" ( $F R=16$; $S R=9)$ and the song "99 Luftballons" ( $F R=16 ; S R=10)$.

\section{DISCUSSION}

The findings revealed that the students' stereotypical images about Germany were multifarious. The 29 cultural stereotypes identified in this study included various country-related aspects, such as sport, science, technology, industry, culture, history, people, language, geography and foods. As Table I demonstrates, there were several overlapping categories among the cultural stereotypes about Germany. This was obviously the case with such groups of images as "cars", "Volkswagen" and "BMW" and also with the groups "Oktoberfest" and "German culture". The presence of the overlapping categories is due to two methodological decisions made by the researchers. First of all, we aimed to identify as many cultural stereotypes as possible because this would give a richer palette of the students' imagery about the TL country. For example, the label "Cars" would be less informative about the category compared to the labels "Volkswagen" and "BMW", which allow a precise and instant grasp of the categories' content. Secondly, the availability of the highly homogenous, albeit overlapping, categories allowed a deeper insight into the cultural stereotypes' salience. For example, the categories "Oktoberfest" and "German culture" retained as separate entities made it possible to deduce that though the image "German culture" ( $\mathrm{n}=4)$ was slightly less frequent compared to

"Oktoberfest" ( $\mathrm{n}=5)$ it had much higher salience. It would not be possible to make this distinction had these two categories been joined.

In many aspects, our findings largely agree with the results of the available 
research literature. For example, the references to science featured prominently in the present study as reflected in the high frequency and salience ranks of science-related images. The similar images had been reported among the widelyheld country stereotypes about Germany and Germans in a study by Katz and Braly (1933). In line with the findings reported by Abrams (2002), Schulz and Haerle (1995) and Taylor (1977), the respondents in our study tended to associate Germany with cars, beer, beautiful landscape, rich culture and interesting history. Furthermore, the Malaysian learners of German shared similar views about the characteristics of the target language with the participants in the previous studies who had described German as a "difficult language" with a "difficult grammar" (Chavez, 2009; Schulz \& Haerle, 1995). Also, the participants in the present study tended to have an overall negative perception about the German language as reflected in the negative mean valence $(M V=-0.4)$ of the category "Language". This result aligns with the general views about German reported by Chavez (2009).

In the current study, the Malaysian students described the German people as "friendly", "punctual", "serious", "determined" and "disciplined". Furthermore, they considered the Germans as people who "have analytical mind" and are "hardworking". These images agree with the characteristics assigned to the German people by the participants in the earlier studies (Abrams, 2002; Katz \& Braly, 1933; Schulz \& Haerle, 1995). It should be noted that there was only one cultural stereotype in the present study that concerned the German people, which was "disciplined people". More importantly, the findings revealed that the students had provided only a few answers mentioning famous Germans. This merits a further discussion. The image of Germany as the "land of poets and philosophers" is one of the older and widely-accepted country stereotypes. For several centuries, great poets, composers, philosophers and artists have been a "part of the cultural canon" in Germany and in the German-speaking countries (Chavez, 2005: 39). The finding that the participants in the present study did not mention German cultural figures does not necessarily mean that they are not familiar with music of Bach or Wagner or that they never heard about Goethe, Kant or Nietzsche. But it does reveal a reality that these cultural figures were not among the most readily available images about Germany. Among the famous Germans mentioned by the respondents were Albert Einstein $(F=2)$, Angela Merkel $(F=2)$, football player Miroslav Klose $(F=1)$, scientist Fritz Haber $(F=1)$ and industrialist Robert Bosch $(F=1)$. However, none of these images was sufficiently frequent to form a cultural stereotype.

One of the unexpected findings in the present study was that "football" was the most frequent $(F=12)$ and the most salient $(S R=1)$ image that the respondents associated with Germany. This result offers a striking difference with the findings 
of the previous studies. Abrams (2002) was the only researcher who reported "soccer" among the language learners' country stereotypes about Germany; however, as the researcher stated, it was also one of the less common country images. Regrettably, we cannot make a comparison regarding salience of this image between the present inquiry and the study done by Abrams because the latter did not measure salience of the language learners' stereotypes about Germany. This limitation points to the need for a more advanced methodology that would allow a more precise measurement and evaluation of the students' images about the TL country. An example of such methodology was presented in the current study.

Despite many similarities in the findings of the present and the previous studies on language learners' stereotypes about Germany, there are some differences that deserve a further discussion. Thus, the Malaysian students not only made references to German cars but also recognized Germany's status as an industrial and technologically-advanced country that has big multinational companies and corporations. These perceptions were lacking in the previous studies on stereotypes about Germany. Also, the participants in this study not only mentioned the image "football" but also demonstrated some knowledge about German football league. This is evidenced in the fact that the image "Bayern Munich team" formed a cultural stereotype about Germany. In contrast to the findings reported by other researchers (e.g., Schulz \& Haerle, 1995), the participants in the current study did not make references to the physical attributes of the German people.

Regarding the students' attitudes toward the TL country, the findings revealed that the language learners' stereotypes about Germany were overall positive. Only 4 out of 29 cultural images had negative mean valences. Three of these images referred to World War II. Importantly, only one of the negative cultural stereotypes had a relatively high salience; this image was "Hitler" $(M V=-1, S R=11)$. The remaining three negative images were among the least salient cultural stereotypes about Germany. These findings reveal that the positive images about the TL country not only dominated in frequency but they also came to the students' minds more readily compared to the negative stereotypes.

Another interesting insight we obtained while analyzing the data was that the students' cultural background had indeed played an important role in forming the images about the TL country, which supported Lippmann's (1965 [1922]) proposition that stereotypes are culturally bound. For example, some images were mentioned far more frequently by the non-Malaysian respondents; among them were "Berlin Wall”, "disciplined people", "World War II", "interesting history" and "beautiful landscape". In addition, several of the images about Germany were mentioned exclusively by the foreign students. These images were "Angela Merkel", "order" and "Munich". However, none of these images could form a cultural stereotype due to the low frequencies. 


\section{CONCLUSION}

The present study demonstrated some approaches and techniques that can be used by applied linguists and language educators to explore and assess language learners' images about the TL country in a more rigorous manner. For example, while the previous studies on the language learners' stereotypes about Germany were only able to report the images frequencies and make some propositions concerning favourability of these images, the current study offered an evidencebased analysis of the learners' attitudes expressed through their stereotypes. Moreover, this study reported salience of the stereotypes about Germany, which had not been done previously.

Among the advantages of using the techniques proposed in this article is the possibility of making comparisons regarding the nature of language learners' country stereotypes across various educational and cultural contexts. From a practical perspective, this knowledge may be used by the language educators and curriculum planners to make empirically-driven decisions regarding the cultural component of the language program that would address and respond to the educational needs of their students. For example, the results of the present study indicated that Malaysian language learners would benefit from a wider and deeper exposure to German high culture and that the language educators need to introduce important cultural figures to their students. Also, the language teachers may want to highlight the great cultural significance of these figures in the context of Germany and German-speaking countries.

\section{REFERENCES}

Abrams, Z. I. (2002). Surfing to cross-cultural awareness: using internet-mediated projects to explore cultural stereotypes. Foreign Language Annals, 35(2), 141153.

Allport, G.W. (1954). The nature of prejudice. Cambridge, Massachusetts: Addison-Wesley Publishing Company.

Chavez, M. (2005). Variation in the beliefs of college students of German about the teaching of culture. Die Unterrichtspraxis / Teaching German, 38(1), 31-43

Chavez, M. (2009). Learners' descriptions of German pronunciation, vocabulary, and grammar: A folk linguistic account. Die Unterrichtspraxis / Teaching German, 42(1), 1-18.

Dlaska, A. (2000). Integrating culture and language learning in institution-wide language programmes. Language, Culture and Curriculum, 13(3), 247-263.

Ehrlich, H. J. \& Rinehart, J.W. (1965). A brief report on the methodology of stereotype research. Social Forces, 43(4), 564-575. 
Forest L.V. \& Silvert, K.H. (1951). A theory of stereotypes. Social Forces, 29(3), 257-262.

Gardner, R.C. \& Lambert, W.E. (1972). Attitudes and motivation in second language learning. Rowley, MA: Newbury House.

Gardner, R.C. \& Smythe, P.C. (1981). On the development of the Attitude/ Motivation Test Battery. Canadian Modern Language Review, 37, 510-525.

Katz, D. \& Braly, K.W. (1933). Racial stereotypes of one hundred college students. Journal of abnormal psychology, 28, 280-290.

Kormos, J. \& Csizér, K. (2007). An interview study of inter-cultural contact and its role in language learning in a foreign language environment. System, 35(2), 241-258.

Kramsch, C. (2000). Second language acquisition, applied linguistics, and the teaching of foreign languages. The Modern Language Journal, 84(3), 311-326.

Lippmann, W. (1965[1922]). Public opinion. New York: Free Press Paperback.

Marín, G. (1984). Stereotyping Hispanics: The differential effect of research method, label, and degree of contact. International Journal of Intercultural Relations, 8(1), 17-27.

Niemann, Y.F., Jennings, L., Rozelle, R.M., Baxter, J.C. \& Sullivan, E. (1994). Use of free responses and cluster analysis to determine stereotypes of eight groups. Personality and Social Psychology Bulletin, 20(4), 379-390.

Nikitina, L. \& Furuoka, F. (2013). "Dragon, Kung Fu and Jackie Chan...": Stereotypes about China held by Malaysian students. TRAMES, 17(2), 175195.

Ryan, G. W. \& Bernard, H.R. (2003). Techniques to identify themes. Field Methods, 15(1), 85-109.

Schulz, R. A. \& Haerle, B.M. (1995). "Beer, fast cars, and ...”: Stereotypes held by U.S. college-level students of German. Die Unterrichtspraxis / Teaching German, 28(1), 29-39.

Spencer-Rodgers, J. (2001). Consensual and individual stereotypic beliefs about international students among American host nationals. International Journal of Intercultural Relations, 25(6), 639-657.

Stangor, C. \& Lange, J.E. (1994). Mental representations of social groups: Advances in understanding stereotypes and stereotyping. Advances in Experimental Social Psychology, 26, 357-416.

Sutrop, U. (2001). List task and a cognitive salience index. Field Methods, 13(3), 263-276.

Taylor, I.C. (1977). Beware of cultural clichés. Die Unterrichtspraxis / Teaching German, 10(2), 108-114. 